\title{
Obras de arte da Companhia Paulista no século XIX: pequeno estudo sobre suas pontes ferroviárias
}

\author{
Tainá Maria Silva, Eduardo Romero de Oliveira*
}

Resumo O presente artigo tem por finalidade investigar questões sumárias sobre as obras de arte ferroviárias, especificamente as pontes do século XIX da Companhia Paulista, estudando seus materiais, sistemas construtivos e profissionais envolvidos na construção. A investigação se justifica pelo fato das obras de arte se mostrarem semelhantes às demais estruturas ferroviárias, se tornando passíveis de maiores investigações no que compete ao campo da arquitetura e da engenharia. Foram consultados os relatórios administrativos da companhia, plantas, fotografias e bibliografias específicas. Efetuado um levantamento inicial de pontes da Companhia Paulista, compreendeu-se o motivo da utilização de determinados materiais bem como sua relação com questões econômicas e profissionais disponíveis.

Palavras-chave: Companhia Paulista, obras de arte, pontes.

\section{Obras de ingeniería de la Companhia Pau- lista en el siglo XIX: pequeño estúdio sobre sus puentes ferroviarios}

Resumen Este artículo tiene como objetivo investigar las obras de ingeniería ferroviarias, específicamente los puentes del siglo XIX de la Companhia Paulista, estudiando sus materiales, sistemas de construcción y profesionales involucrados en la construcción. La investigación se justifica por el hecho de que las obras de ingeniería son similares a otras estructuras ferroviarias y están sujetas a una mayor investigación en el campo de la arquitectura e ingeniería. Se consultaron informes de gestión de la empresa, planos, fotografías y bibliografías específicas. Después de una encuesta inicial de los puentes de Companhia Paulista, se entendió la razón del uso de ciertos materiales, así como su relación con los problemas económicos y profesionales disponibles.

Palabras clave: Companhia Paulista, obras de ingeniería, puentes.

\section{Engineering works from Paulista Company at 19th century: small study about your railway bridges}

\begin{abstract}
This article aims to investigate summary questions about railway's engineering works, specifically the nineteenth century bridges of Companhia Paulista, studying their materials, construction systems and professionals involved in construction. The investigation is justified by the fact that the engineering works are similar to other railways structures, becoming subject to further investigation in architecture's and engineering's domain. Company management reports, blueprints, photographs and specific bibliographies were consulted. After an initial survey of Companhia Paulista's bridges, the reason for the use of certain materials as well as their relationship with available economic and professional issues was understood.
\end{abstract}

Keywords: Paulista Company, engineering works, bridges. 
$-E$

sta investigação surgiu a partir do estudo de mestrado da autora que visava compreender a arquitetura de oficinas ferroviárias, tendo como objeto de estudo as oficinas ferroviárias de Jundiaí da Companhia Paulista de Estradas de Ferro (CPEF) (SILVA, 2019). Durante a leitura dos relatórios da companhia, foi possível identificar um certo volume de informações voltado às estruturas ferroviárias nomeadas de "obras de arte" e que apontavam para uma consonância com o então objeto de estudo como materiais construtivos e fornecedores. Dessa forma, foi realizada uma breve investigação sobre essas estruturas.

As informações aqui dispostas foram obtidas, inicialmente, através da leitura dos relatórios administrativos da CPEF $^{1}$ entre os anos 1869 a 1900, onde foi encontrada a maior parte dos dados como: materiais, sistemas construtivos, fornecedores, profissionais e localização de tais estruturas. Outras bibliografias foram consultadas com a finalidade de obter informações específicas como: qual a atuação de certos fornecedores, qual o conhecimento técnico da época, entre outros. Especificamente sobre este último, a obra de Picanço (1892) e alguns tratados ferroviários foram de suma importância. Eventualmente, estendeu-se a leitura dos relatórios da companhia para além do século XIX com a finalidade de identificar informações pontuais. Também foi efetuada a leitura de alguns relatórios de outras companhias ferroviárias com a mesma finalidade.

De acordo com os relatórios da CPEF, foi identificado que obra de arte corresponde às seguintes estruturas: pontes, pontilhões, viadutos, bueiros e passagens americanas (passagem de nível com cancela). Segundo Picanço (1892) e Maia (1897), também podem ser incluídos na lista: túneis, galerias de abrigo, muros de arrimo e revestimentos. Geralmente são estruturas executadas de maneira excepcional e que tem a finalidade de dar suporte ao bom funcionamento da via. No caso, pontes visam superar cursos d'água; pontilhões visam superar depressões do terreno; bueiros visam drenar água em pontos estratégicos que possam inundar; passagens americanas visam proteger o fluxo de pedestre e assim por diante.

Interessante notar que o termo "obra de arte" no contexto ferroviário pode ser melhor compreendido através do idioma francês. No francês, há duas palavras para definir "obra": ouvrage e oeuvre. Esta última, oeuvre, diz respeito a uma obra acabada, um produto final; enquanto a primeira, ouvrage, diz respeito às todas as ações que envolvem a constituição de uma obra como produto final. Na língua portuguesa também há essa

* Tainá Maria Silva é Arquiteta e Urbanista, Mestre pela Universidade Estadual Paulista Júlio de Mesquita Filho, ORCID $<$ http://orcid.org/0000-00034176-0869>. Eduardo Romero de Oliveira é Historiador, professor da Universidade Estadual Paulista Júlio de Mesquita Filho, ORCID $<$ https://orcid.org/0000-0002$1287-4798>$ diferenciação nos significados: uma obra pode ser um produto acabado ou mesmo o ato de se construir. No entanto, no idioma francês, uma obra de arte (ferroviária) é traduzida como ouvrage d'art, o que denota que os processos que antecedem o produto final são mais importantes ou dignos de maiores atenções. Nesse caso: o projeto, os materiais, o sistema construtivo e a construção em si.

Se valem dessa complexidade com maior relevância as pontes ferroviárias, estruturas da qual o presente estudo optou por restringir pelo fato de haver maior número de 


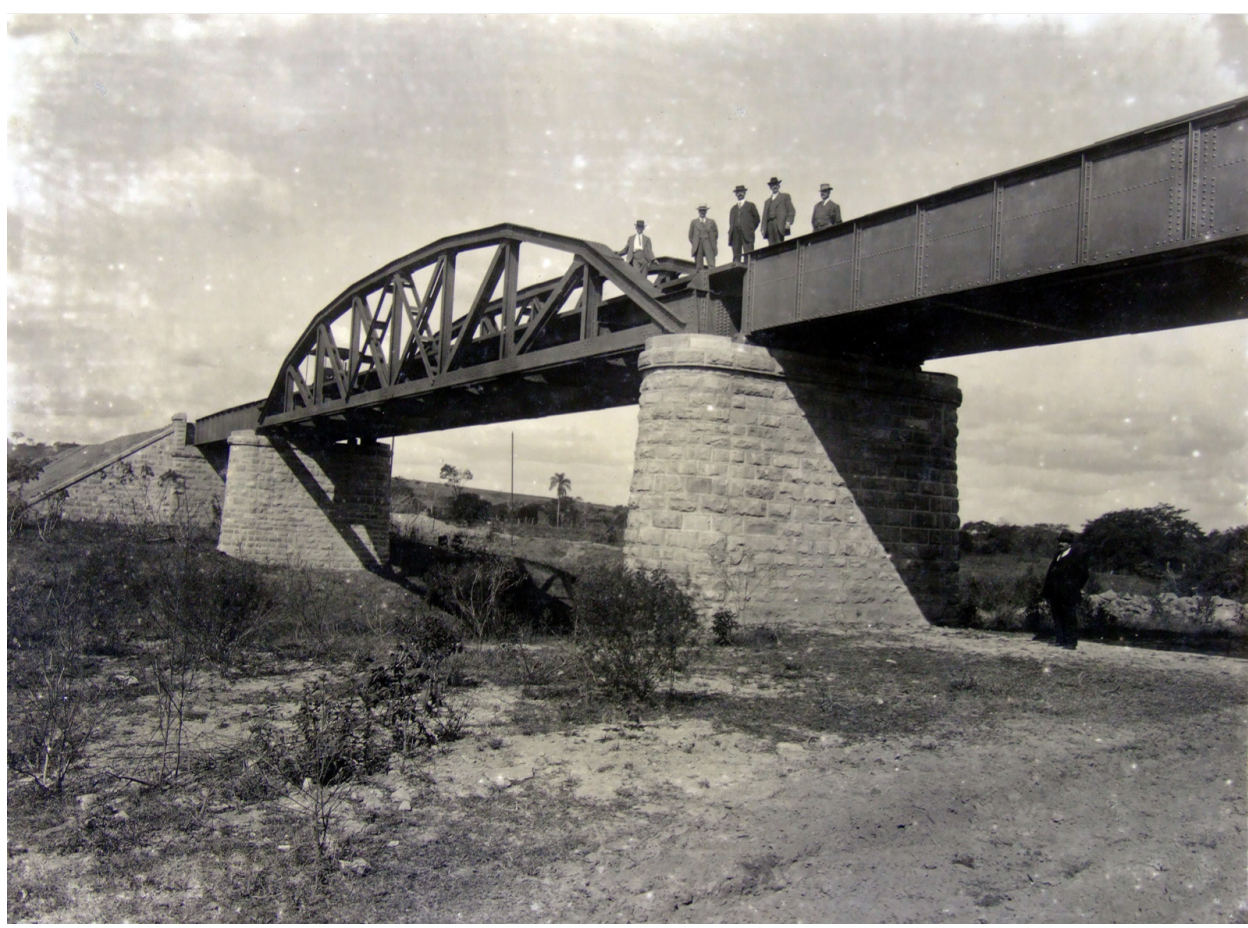

Figura 1: Ponte sobre o Rio Corumbataí, s.d. Fonte: Acervo do Museu da Companhia Paulista.

\footnotetext{
1 Relatórios disponíveis digitalmente no site do projeto Memória Ferroviária <https://memoriaferroviaria.rosana.unesp. br/?page_id=1762>.
}

material dedicado a essa estrutura do que às demais. Embora os relatórios administrativos da CPEF terem privilegiado as pontes, eventualmente a presente análise abrangerá as demais obras de arte.

O "Album ilustrado da Companhia Paulista" (PÉREZ, 1918), chegou a apontar algumas obras de arte consideradas de destaque pela companhia, sendo elas: a ponte sobre o Rio Tietê, de Ayrosa Galvão; as três pontes sobre o Rio Mogi Guaçu (Emas, Guatapará e Porto Ferreira); a ponte sobre o Rio Atibaia; sobre o Corumbataí (Figura 1) e algumas outras menores.

Através dos relatórios da CPEF, toma-se conhecimento das centenas de pontilhões e bueiros que a companhia construiu (COMPANHIA PAULISTA, 1893) e pode-se identificar 32 pontes de alguma relevância construídas no século XIX e ainda outras 8 pontes construídas na primeira década do século XX (vide tabela em anexo). Ressalta-se que esse número diz respeito somente às estruturas nomeadas de fato como ponte pela companhia pois, curiosamente, ela não adotava um padrão para essa nomenclatura: foi identificado que na maioria dos relatórios nomearam "ponte" aquelas estruturas com extensão superior a 5 metros, denominando estruturas menores como "pontilhão". No entanto, alguns relatórios chegaram a mencionar pontilhões de 5, 6 e até 7 metros (COMPANHIA PAULISTA, 1880 - 1883), o que aponta a falta de padrão da companhia. Sugere-se aqui que a CPEF preferiu, eventualmente, nomear como pontilhão a estrutura que superava vãos maiores que 4 metros quando estes não se encontravam em áreas alagadiças. De qualquer forma, para o presente estudo, por seu caráter primário, preferiu-se manter a nomenclatura utilizada pela CPEF independentemente dessa heterogeneidade, mas destacando, sempre que possível, a extensão das pontes. 


\section{Materiais}

Os materiais das obras de arte do século XIX apontam para uma evolução através dos anos: inicialmente utilizavam madeira, posteriormente a trocaram por ferro pelas já conhecidas vantagens de durabilidade e baixo custo de manutenção e no século XX o material principal se torna o concreto armado. A utilização da madeira se deu em larga escala nas atividades ferroviárias, estando presente em edificações, obras de arte, postes, dormentes de trilhos, na construção de vagões de carga ou carros de passageiros e na alimentação de equipamentos oficinais e locomotivas - como fonte de energia para maquinas a vapor. Para este último, a partir da primeira década as companhias passaram a formar seus próprios hortos para produção industrial (fornecimento de dormentes e postes), tamanha a importância do material. Nas obras de arte, a utilização da madeira se dava de maneira mais frequente nas pontes e pontilhões.

A primeira ponte da CPEF foi construída em Jundiaí em 1870 (COMPANHIA PAULISTA, 1870), e apesar de ter sido utilizado materiais metálicos, notou-se que a madeira e ferro foram os materiais mais utilizados pela Companhia ao longo dos anos - e assim perduraria até o final do século XIX. Em alguns relatórios, são citadas pontes de madeira que posteriormente foram substituídas por materiais metálicos ou receberam o acréscimo do metal em peças específicas, o que era visto como uma espécie de melhoria da via. Não foi possível identificar todos os critérios que a Companhia seguia para fazer a troca do material, mas um deles estava condicionado à segurança e resistência do ferro em relação à madeira (COMPANHIA PAULISTA, 1883; 1885; 1888; 1889; 1891).

O uso do metal, apesar de tudo, não era inicialmente predominante neste tipo de obra. O relatório de 1903 afirmava que "em todos os ribeirões e córregos de alguma importância existem sólidas pontes de aroeira" (COMPANHIA PAULISTA, 1903, p.12), contudo, havia um esforço por parte da Companhia em eliminar suas obras de arte de madeira, o que esbarrava em limitações no uso das peças metálicas para pontes.

Destaca-se que, apesar de Picanço ter delimitado a madeira aroeira como boa opção para obras hidráulicas, ao mesmo tempo comenta que pontes de madeira eram comumente utilizadas em "estradas de ferro economicas" (PICANÇO, 1892, p.217). O tratado de Perdonnet (1856) também comenta sobre essa baixa popularidade do material para vias mais importantes na Europa: o engenheiro afirma que, por conta da durabilidade, ela é comumente empregada em vias menos importantes, o que dá pistas para compreender a aplicação de determinado material em detrimento de outro. Para Paulo Cirne Maia (1897), a madeira em pontes deveria ser utilizada somente como material provisório pela sua falta de segurança, embora o próprio autor reconheça que a substituição do material nem sempre ocorria.

A utilização do ferro em pontes da CPEF ocorria, na maioria das vezes, de duas maneiras: as peças poderiam ser fundidas e moldadas nas próprias oficinas da companhia ou então eram importadas peças ou a estrutura inteira. No primeiro caso, acredita-se que as peças fundidas se tratam de trilhos velhos: essa hipótese se deriva do histórico das companhias férreas paulistas de reciclarem esse material, como pode-se observar na leitura de diversos relatórios, e também do fato de ser mencionado a utilização de trilhos velhos em algumas pontes (COMPANHIA PAULISTA, 1888; 1891; 1907). 
2 Adaptado para a língua portuguesa corrente. Do original "dos 43 pontilhões substituidos, 29 vierão da Belgica" (COMPANHIA PAULISTA, 1892, p.153).
No segundo caso, cabe mencionar que havia uma diferença entre importar peças e importar uma estrutura completa (nomeada também como superestrutura). Por parte da CPEF, a importação de pontes completas ocorreu pontualmente, já a importação de peças avulsas de ferro ocorria de maneira mais abundante e, até o momento, supõe-se que o motivo tenha sido o custo-benefício. No relatório de 1892, a companhia apontou que "dos 43 pontilhões substituídos, 29 vieram da Bélgica"2 (COMPANHIA PAULISTA, 1892, p.153). A origem provável desses pontilhões são as oficinas ferroviárias de Braine-Le-Conte (já demolidas), que exportaram vigas para um outro pontilhão em Campinas, segundo o mesmo relatório. Nos relatórios de 1881 e 1891 também são indicadas compras de peças metálicas para as pontes, com origem europeia (COMPANHIA PAULISTA, 1881; 1891).

A compra numerosa dessas peças reforça a hipótese de estar relacionada ao custobenefício, uma vez que os pontilhões não possuíam valor estético e não possuíam uma importância - ao menos não que pudesse ser descrita exaustivamente nos relatórios como faziam com certas pontes. Além disso, o vão curto de um pontilhão, em comparação a uma ponte, não justificaria a necessidade de utilização de materiais metálicos quando a companhia construía pontes de madeira.

Outro material bastante utilizado pela CPEF para a composição de obras de arte foi a pedra e o tijolo, isso porque eles compunham o sistema construtivo de praticamente todas as obras. Algumas eram, inclusive, identificadas por esse material, como os bueiros que possuíam variados tipos: capeado, coberto (simples e duplo), aberto (simples e duplo) e em arco.

Para Maia (1897), seria conveniente a construção de uma ponte de alvenaria somente se o curso d'água a ser superado não excedesse 12 metros. Segundo Picanço (1892), os tijolos de barro das obras ferroviárias geralmente atendiam às dimensões de 27×18×06 centímetros, medida condizente à encontrada em algumas visitas técnicas às obras ferroviárias da CPEF. Segundo mesmo autor, as pedras mais utilizadas no século XIX eram: granito, gneiss, basalto e porphyro.

O tipo de pedra requerido para as obras de arte poderia ser encontrado ao longo da via, como aponta o relatório de 1870, onde a companhia menciona que, durante a implantação de trilhos, encontrou pedras "próprias para as obras d'arte" (COMPANHIA PAULISTA, 1870, p. 19). Para a produção de brita para o lastro dos trilhos, as fotografias registram atividades de algumas pedreiras como a "Pedreira do Tatu" e a "Pedreira do Britador" (vide Acervo do Museu da Companhia Paulista). A origem dos tijolos, no entanto, não foi possível identificar.

A reciclagem de materiais para composição de obras de arte era algo recorrente na CPEF, tal qual pudemos observar também na Companhia Mogiana. A CPEF, além de utilizar trilhos velhos para estrutura de ponte, os utilizou para construir um sistema rudimentar de represamento e estruturas de barracões. Consta também que a CPEF fez pontilhões em suas oficinas reutilizando algumas vigas velhas de outros pontilhões que precisaram ser substituídos. Outra prática da companhia era reaproveitar estruturas metálicas de pontes antigas, cortando suas vigas em menores tamanhos e aplicando-as em pontes ou pontilhões de menor vão (COMPANHIA PAULISTA, 1885; 1891; 1892; 1893; 1902; 1907). A Companhia Mogiana chegou a utilizar trilhos velhos em vigas de 
Figura 2: Construção de bueiro de tijolos com armação de madeira, s.d. Fonte: Acervo do Museu da Companhia Paulista. bueiros, pontilhões e passagens americanas (COMPANHIA MOGYANA, 1885; 1886; 1891). Ambas as companhias também utilizavam trilhos velhos para fazer postes ao longo da via [SILVA, OLIVEIRA 2019].

\section{Sistemas construtivos}

Os sistemas construtivos das obras de arte não fogem da convencional alvenaria. A alvenaria de pedra com argamassa de cal podia ser visualizada tanto no embasamento das pontes quanto no paramento de túneis, bueiros em arco e alguns pontilhões. Para os bueiros, poderiam ser construídos sistemas estruturais em alvenaria de pedra, alvenaria de pedra seca, alvenaria de tijolo (Figura 2) ou mesmo combinado de pedra com tijolo. Seu dimensionamento se sustentava em cálculos específicos e a construção deveria seguir também certos rigores já compilados por Picanço (1892).

Quando fosse necessário, a CPEF costumava utilizar o tijolo de barro em substituição à pedra, que possuía, na maioria das vezes, a mesma aplicabilidade, compondo o sistema construtivo das obras de arte. Essa prática segue a recomendação de Maia (1897) e também de Picanço que, tratando de bueiros (Figura 2), comenta que "quando não há muita pedra perto da obra, as paredes podem ser feitas com alvenaria de tijolos" (PICANÇO, 1892, p.133), deixando o leitor subentender que a preferência por um ou outro material para compor o sistema construtivo era uma questão também de logística. Essa neutralidade perante a escolha de pedra ou tijolo aparece sutilmente também na obra de Perdonnet (1856, p.352), onde o autor comenta que as pontes se distinguem em "madeira; em pedra ou tijolo; em ferro; em ferro fundido ou em chapa metálica".

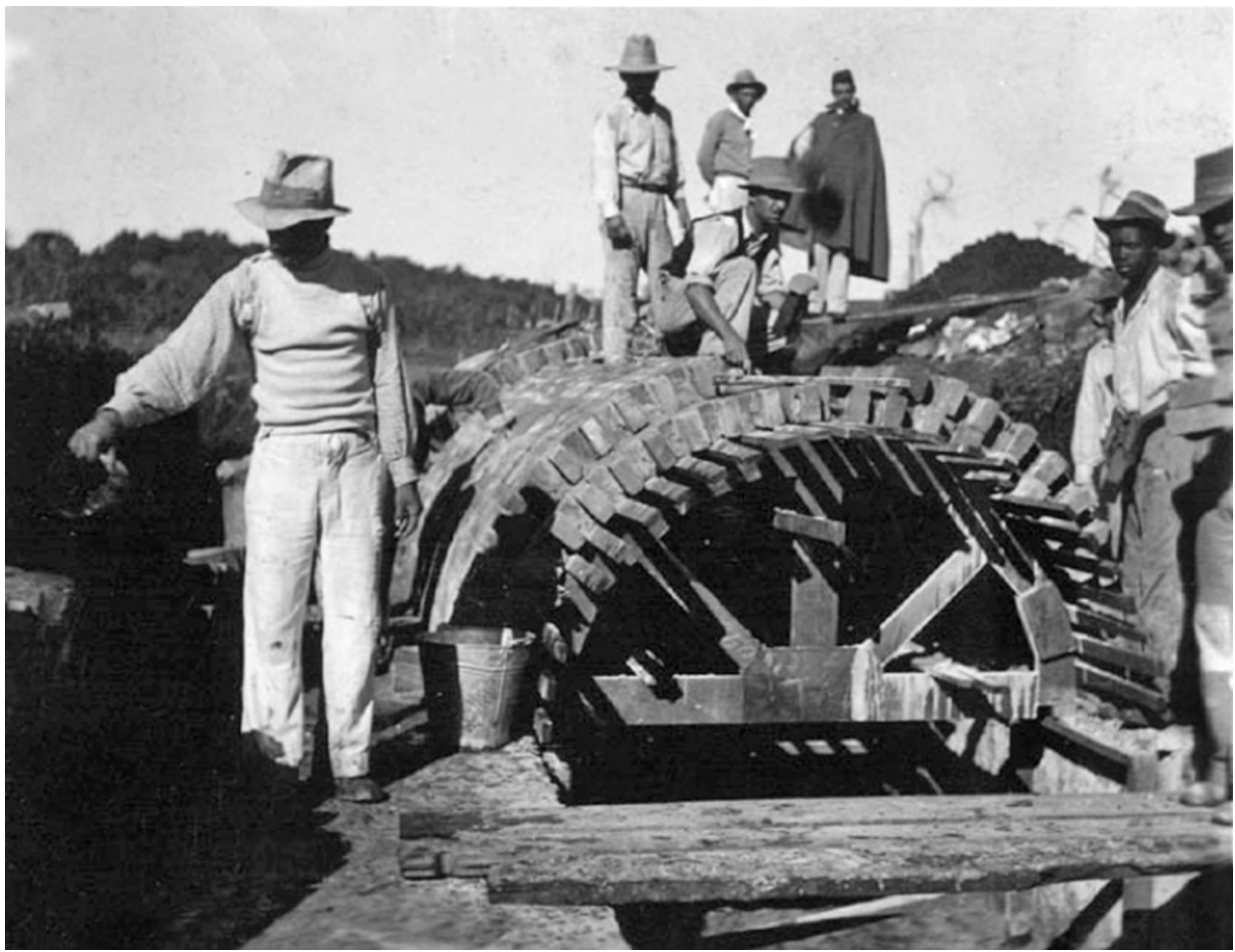


3 Identificou-se pontes da Phoenix Bridge em variadas localidades brasileiras, vide Silva (2019).
No século XX, o sistema construtivo das obras de arte passa a ser de concreto armado, onde é utilizada a forma de madeira para a concretagem (feita manualmente); aguarda-se a cura e então é realizada a remoção dos escoramentos de madeira.

A respeito das pontes, as estruturas de sustentação deveriam ser estáveis o bastante para suportar a trepidação, o peso do trem além do próprio peso da superestrutura. Os pegões (apoio da ponte construído dentro da água) detinham a maior atenção no que se referisse aos sistemas construtivos de pontes. Segundo Perdonnet (1856), o material escolhido para compor esses sistemas definiria a estabilidade da mesma e, por conseguinte, este deveria seguir certos rigores construtivos. Em um exemplo, o engenheiro comenta que para determinado caso a alvenaria em tijolos é excelente para absorver a trepidação. Para Maia (1897), os pilares são uma forma eficiente de reduzir o vão da estrutura metálica e, por conseguinte, reduzir o custo.

Algumas pontes da CPEF apontam para a utilização de pegões em alvenaria sobre rocha, o que era considerado pela companhia uma segurança de solidez. Quanto à superestrutura, esta costumava ser dimensionada a partir da treliça tipo Pratt (treliça com elementos diagonais, mais barata de construir) e também da treliça Schwedler (em arco, com banzo curvo, também para pequenas extensões). Em verdade, esse modelo não é exclusivo da CPEF, mas sim um tipo recorrente à época, relacionado à empresa norte-americana Phoenix Bridge. Segundo Winpenny (1996). A Phoenix Bridge chegou a patentear a grande maioria de seus modelos de ponte, no entanto, não foi possível identificar se ela é de fato a precursora do tipo. ${ }^{3}$

Visualizando pontes de outras companhias, comumente pode-se encontrar sistemas mais simples compostos por um tabuleiro (estrado) de madeira do qual o pegão poderia ser formado por alvenaria de pedra ou alvenaria de tijolo ou mesmo substituído por cavaletes. Não foi possível identificar este último tipo de ponte na CPEF.

O cimento apontado por Perdonnet (1856) e Picanço (1892) como o mais adequado para obras hidráulicas é o romano. Nas obras da CPEF, no entanto, não foi possível identificar se esse material foi utilizado.

Ao final da construção de uma obra de arte, ela deveria ser posta à prova de solidez, que consistia em um teste de resistência do qual um trem com carros carregados deveria passar diversas vezes sobre a obra de arte e em variadas velocidades (PICANÇO, 1891).

\section{Profissionais e fornecedores}

No caso dos trabalhos na via férrea, a construção de obras de arte ficava condicionada não somente à técnica ou tecnologia, mas também à habilidade do profissional. O perfil de tais profissionais da CPEF já foi tema de estudo de Lanna (2016).

Como a grande maioria das obras de arte estavam condicionadas à topografia, era de se esperar que elas fossem previstas quando fosse efetuado um projeto de via férrea, comumente nomeado pela CPEF de "plano". Com o primeiro plano aprovado, a companhia abriu chamada pública para construção e elegeu seus 
${ }^{4}$ Apesar desse relatório afirmar que os empreiteiros fariam todas as obras de arte do trecho, no contrato assinado entre as partes não há menção explícita às essas obras.

5 Ayrosa Galvão esteve envolvido com outros trabalhos ferroviários tanto na CPEF quanto em companhias do Sul do país (ALMANAK LAEMMERT, 1897).

6 Balbino Peçanha foi mestre das oficinas de Jundiaí (COMPANHIA PAULISTA, 1904).

7 Roberto Marinho de Azevedo se formou em engenharia pela Escola Politécnica do Rio de Janeiro, trabalhou na CPEF e na eletrificação da companhia Central do Brasil (PAIM, 1982)

Figura 3: Construção da ponte de Ayrosa Galvão sobre o Rio Tietê, 1902-3. Fonte: Acervo do Museu da Companhia Paulista. primeiros empreiteiros: Ângelo Thomaz do Amaral, Heitor Rademaker Grünewald e João Pereira Darrigue Faro. Estes trabalhariam no trecho Campinas-Jundiaí com contrato entre 1870 e 1872 e efetuariam todas as obras desse ramal, incluindo as obras de arte ${ }^{4}$ (COMPANHIA PAULISTA, 1870). Dos três distintos empreiteiros, foi identificado que habitaram a cidade do Rio de Janeiro e se envolveram em obras ferroviárias anteriores às da CPEF. Em paralelo, Ângelo Thomaz do Amaral e João Pereira Darrigue Faro chegaram a exercer atividades políticas no Brasil e Heitor Rademaker Grünewald foi um arquiteto que trabalhou com seu irmão (também arquiteto, formado na École des Beaux-Arts de Paris) em diversas obras brasileiras (SOUZA; AMORA, 2014).

Diversos empreiteiros passaram pela CPEF, na maioria das vezes contratados por chamada pública para exercer serviços previamente determinados. Somente na construção da grande ponte sobre o Rio Tietê (Figura 3), por exemplo, é possível encontrar nomes como Ayrosa Galvão ${ }^{5}$, Balbino Peçanha ${ }^{6}$ e Roberto Marinho de Azevedo $^{7}$ (COMPANHIA PAULISTA, 1903; 1904; 1905), todos profissionais que já tinham relação com o trabalho nas ferrovias. Como exceção, Joaquim Dutra, o pintor da referida ponte, aponta para uma curiosidade: existe a possibilidade de tal pintor ser o famoso Joaquim Miguel Dutra que, antes de iniciar sua carreira artística na primeira década do século XX, executava serviços ordinários de pintura para se manter financeiramente (JOAQUIM..., 2017).

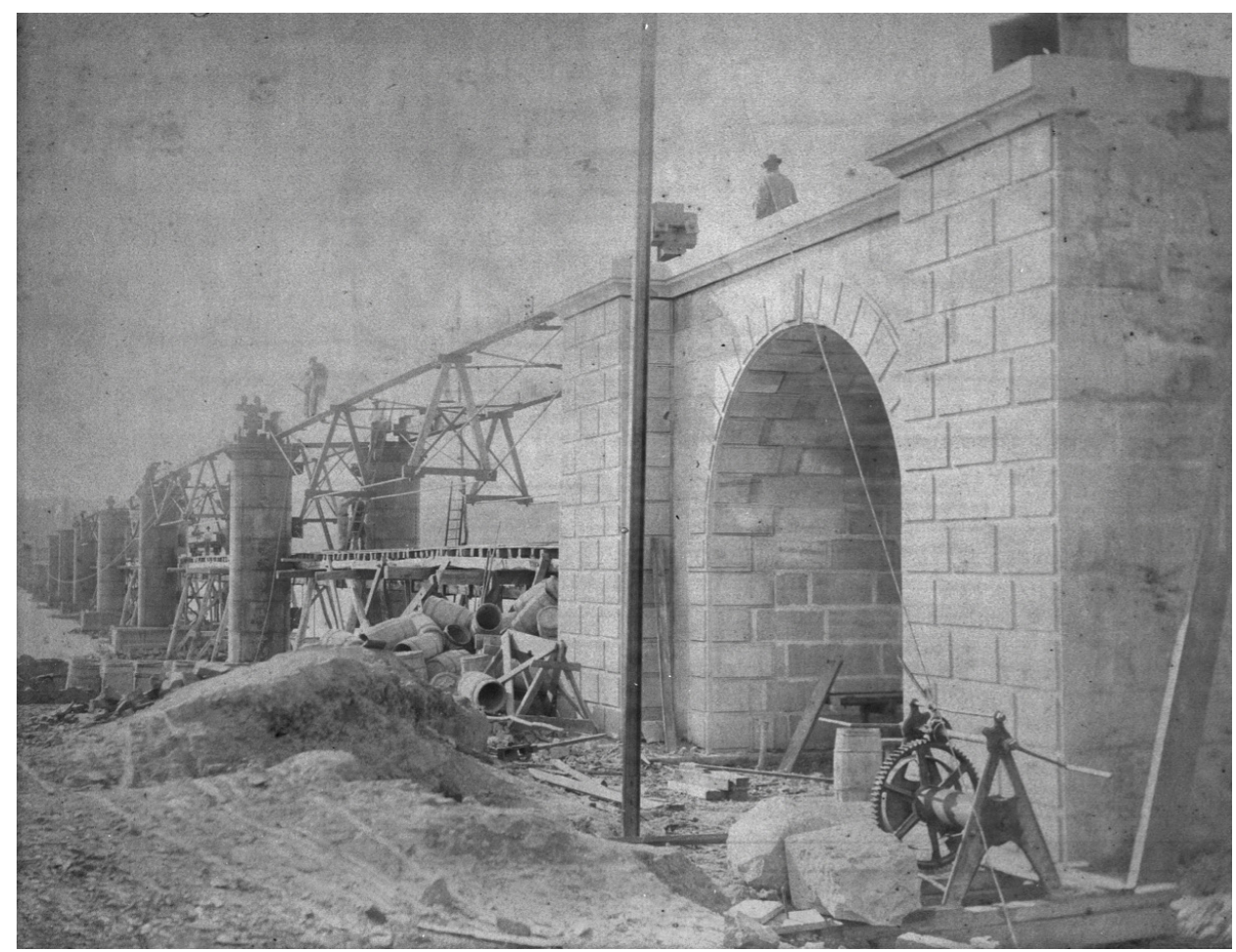


Pode-se identificar também que a CPEF recorria constantemente a companhias estrangeiras para compra de materiais para as obras de arte. Quando um fornecedor possuísse pontos de venda fora do Brasil, a CPEF enviava um de seus profissionais ao país do fornecedor para que esse pudesse efetuar a escolha, negociação e acompanhamento até a postagem por navio (COMPANHIA PAULISTA, 1871). Em outras situações, no entanto, nota-se que a CPEF tinha uma relação com a empresa londrina Fry, Miers \& Co e que a nomeou como "correspondentes" e também "agentes da Companhia Paulista em Londres" (COMPANHIA PAULISTA, 1877, p.17 e p.88), onde estes fariam o papel do funcionário e escolheriam os fornecedores.

A Fry, Miers \& Co foi uma empresa de engenharia estabelecida em Londres, Inglaterra, sob a administração de Francis Charles Miers e Alexander Fry. Em 1845, Francis Charles Miers abriu sua primeira empresa de engenharia no Rio de Janeiro, envolvida com construção de moinhos d'água, e participou da superintendência da Fundição Ponta d'Areia, na mesma cidade. Nos dez anos seguintes esteve envolvido na construção de navios, fechou contratos com o governo brasileiro e ficou responsável por diversas estruturas de ferro relacionadas a portos (FRANCIS..., s.d; FRY, MIERS \& CO, s.d). As pontes aqui descritas, no entanto, não foram encomendadas pela Fry, Miers \& Co. Apesar disso, destaca-se a empresa como importante participante no ramo de transações internacionais, sendo uma porta-voz da CPEF na Europa que pode apontar um método alternativo da Companhia em efetuar importações entre os anos de 1871 até a década de 1890 .

A primeira ponte de importância da CPEF foi encomendada através do modelo de envio de funcionário à Europa. O primeiro engenheiro a fazer esse tipo de procedimento foi João Ernesto Viriato, que em sua primeira ida esteve encarregado de comprar "trilhos, pontes de ferro e algum trem rodante" (COMPANHIA PAULISTA, 1870, p.5) e acabou por comprar "carris e mais acessórios da via permanente - pontes, tectos para officinas, machinas, utensis, aparelhos como giradores etc" (COMPANHIA PAULISTA, 1871, p.4). Sobre essa ponte, acredita-se que tenha sido comprada da empresa londrina De Bergue \& Co pelo fato de constar seu nome na tabela de compra de materiais, por ser a única companhia que produzia pontes entre os demais nomes da tabela e também pelo fato da De Bergue, à época, estar envolvida com importantes trabalhos de pontes (DE BERGUE..., s.d.). A localização exata dessa primeira ponte, no entanto, não pode ser identificada.

Uma outra ponte metálica encomendada da Europa foi aquela projetada pela Andrew Handyside \& Co. O engenheiro Walter J. Hammond se deslocou até a Europa e, apesar de solicitar o auxilio da Fry, Miers para compra de trilhos, não fica claro no relatório se ele solicitou auxilio também na compra da ponte (COMPANHIA PAULISTA, 1874). Essa ponte da Andrew Handyside foi construída para superar o Rio Piracicaba no ramal Jundiaí-Cordeiro; tinha cerca de 45 metros de extensão (COMPANHIA PAULISTA, 1875) e, até onde foi possível identificar, foi uma das poucas pontes dessa empresa exportadas à América do Sul. Uma possível ilustração sobre ela encontra-se no livro de Adolpho Pinto (1903).

Outra importante fornecedora de pontes foi a Phoenix Bridge \& Co que, em 1902, exportou uma ponte metálica para a cidade de Mogi Guaçu, para superar o rio de mesmo nome (COMPANHIA PAULISTA, 1902) (Figura 4). A Phoenix Bridge \& Co 


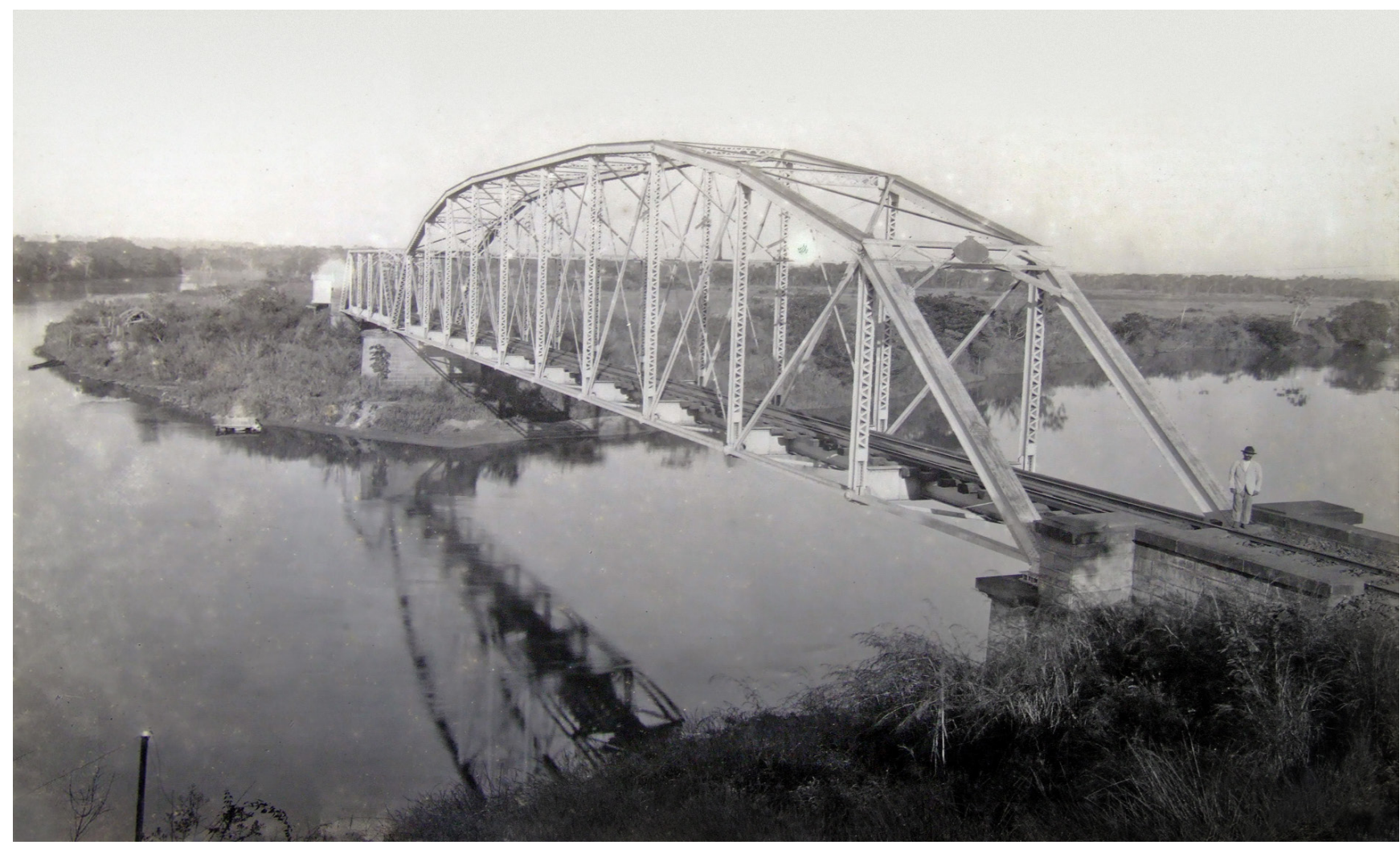

Figura 4: Ponte da Phoenix Bridge com treliça tipo Schwedler sobre o Rio Mogi Guaçu, s.d. Fonte: Acervo do Museu da Companhia Paulista. foi uma empresa norte-americana de construção de pontes subsidiária da Phoenix Stee/e Phoenix Iron. Chegou a dominar o mercado norte-americano e pode inclusive efetuar exportações com o auxílio de um catálogo de peças para pontes e estruturas (WINPENNY, 1996). Além do preço vantajoso que a Phoenix Bridge oferecia, suas estruturas de ponte serviam também outros tipos, como estrutura de cobertura. Inclusive a empresa chegou a fornecer para a CPEF a estrutura de cobertura para as oficinas de Jundiaí. Isso se devia ao fato da empresa trabalhar com peças que poderiam compor diferentes treliças. Nesse caso, maiores investigações são necessárias para identificar se as obras de arte foram construídas a partir de outras estruturas ou o inverso.

Outro fato importante sobre a Phoenix Bridge é que o seu baixo preço esteve, por muitas vezes, relacionado à baixa qualidade do serviço (WINPENNY, 1996). Além disso, uma companhia que exportava peças não poderia garantir uma mão-de-obra qualificada quando esta estivesse fora de seu território. Os dados sobre a construção desta ponte em Mogi Guaçu encontram-se no relatório da Companhia de 1902, num rico e extenso descritivo. Nele, são apontados alguns detalhes da execução; da montagem da superestrutura e do teste de resistência. 


\section{Considerações finais}

No início das investigações, supunha-se que as obras de arte do século XIX da Companhia Paulista tinham sido importadas, como um produto da arquitetura e engenharia de ferro. No entanto, percebeu-se que muitas pontes eram constituídas, majoritariamente, em madeira e alvenaria, denotando uma certa independência por parte da Companhia em relação ao mercado exportador de peças metálicas - ao menos no que dissesse respeito às obras de arte.

Nesse estudo notou-se também uma ampla variedade de materiais e sistemas construtivos que podiam ser combinados entre si, formando uma verdadeira miscelânea construtiva. De acordo com a literatura internacional consultada, a obra de Perdonnet (1856) mostra que essa miscelânea também acontecia em países europeus e que a escolha de determinado material ou sistema estava condicionada aos custos, logística e também à classificação da linha. Ou seja: o conhecimento de uma ou outra obra de arte ferroviária deve englobar essas questões e a classificação por tipologias pode ser custosa.

Dessa forma, conclui-se que as obras de arte do século XIX da Companhia Paulista representam o saber técnico e prático da época e da região, ao mesmo tempo que englobam recomendações já conhecidas em território europeu. Aos futuros estudos, sugere-se que sejam englobados os manuais ferroviários do século XIX de origem nacional e francesa.

\section{Agradecimentos}

O presente texto foi escrito a partir da pesquisa de mestrado da autora junto ao Programa de Pós-Graduação em Arquitetura e Urbanismo da Universidade Estadual Paulista "Júlio de Mesquita Filho", orientada pelo Professor Doutor Eduardo Romero de Oliveira. Os agradecimentos são dirigidos à Fundação de Amparo à Pesquisa do Estado de São Paulo (FAPESP) pelo financiamento das pesquisas que resultaram nesse texto (Proc.N 2017/10302-5; 2018/01711-1; 2018/23340-5).

\section{Referências bibliográficas}

Almanak Laemmert do Rio de Janeiro para 1897. Rio de Janeiro: Companhia Typographica do Brazil, 1897, 54 Anno, p. 745. Disponível em <http://memoria.bn.br/DocReader/313394/14589> Acesso em 15.11.19.

COMPANHIA MOGYANA. Relatório da Diretoria da Companhia Mogyana para sessão da Assembléa Geral. São Paulo: Typ. a vapor Jorge Seckler, 1885 - 1886.

. Relatório da Diretoria da Companhia Mogyana para sessão da Assembléa Geral. São Paulo: Typ. Companhia Industrial, 1891.

COMPANHIA PAULISTA. Relatório da Diretoria da Companhia Paulista de Vias Ferreas e Fluviaes para a sessão da Assembléa Geral. São Paulo: Typographia do Correio Paulistano, 1869 - 1871, 1877, 1881, 1883.

. Relatório da Diretoria da Companhia Paulista de Vias Ferreas e Fluviaes para a sessão da Assembléa Geral. São Paulo: Jorge Seckler \& Comp., 1885, 1888 - 1889, 1891. 
COMPANHIA PAULISTA. Relatório da Diretoria da Companhia Paulista de Vias Ferreas e Fluviaes para a sessão da Assembléa Geral. São Paulo: Jorge Companhia Industrial de São Paulo, 1892 - 1893.

. Relatório da Diretoria da Companhia Paulista de Vias Ferreas e Fluviaes para a sessão da Assembléa Geral. São Paulo: Vanorden \& Cia, 1902 - 1905, 1907.

CORREIO PAULISTANO, número 17.888, 11 de maio de 1913. Disponível em <http://200.144.6.120/uploads/acervo/periodicos/jornais/BR_APESP_CPNO_19130511. pdf> Acesso em 28.06.18

DE BERGUE \& CO. Graces Guide, s.d. Disponível em <https://www.gracesguide.co.uk/De_Bergue_and_Co>. Acesso em 13.07.18

FRANCIS Charles Miers. Graces Guide, s.d. Disponível em <https://www.gracesguide.co.uk/ Francis_Charles_Miers>. Acesso em 29.06.18

FRY, MIERS \& CO. Graces Guide, s.d. Disponível em <https://www.gracesguide.co.uk/Fry, Miers_and_Co>. Acesso em 29.06.18

GAMA, Ruy. A tecnologia e o trabalho na história. São Paulo: Nobel - Editora da Universidade de São Paulo, 1986.

JOAQUIM Miguel Dutra. Enciclopédia Itaú Cultural. 2017. Disponível em <http://enciclopedia. itaucultural.org.br/pessoa21353/joaquim-miguel-dutra> Acesso em 03.07.18

MAIA, Paulo Cirne. Obras d'arte e orçamentos. Rio de Janeiro: Livraria Internacional F. Briguiet et Cia, 1897.

PAIM, Antonio. Por uma universidade no Rio de Janeiro. In SCHWARTZMAN, Simon. Universidades e Instituições científicas no Rio de Janeiro. Brasília: CNPq, 1982. Disponível em <http://www.schwartzman.org.br/simon/rio/paim_rio.htm\#_ftn1> Acesso em 27.05.18.

PÉREZ, Filemón. Album illustrado da Companhia Paulista de Estradas de Ferro. São Paulo: s.e., 1918.

PICANÇO, Francisco. Diccionario de estradas de ferro e sciencias e artes accessorias. Rio de Janeiro: H. Lombaerts \& comp, 1892. Disponível em: <https://archive.org/details/diccionariodees00costgoog>. Acesso em 30.03.2017.

PINTO, Adolpho Augusto. História da viação pública de S. Paulo. São Paulo: Typographia e papelaria Vanorden \& Cia, 1903.

SANCHIZ. Juan Cano. Reactivation of industrial heritage sites in Spain and The São Paulo State: A transatlantic approach to na international patrimony. In Trans-Atlantic Dialogues on Cultural Heritage. Ironbridge International Institute for Cultural Heritage, University of Birmingham, 2016.

SILVA, Tainá Maria; OLIVEIRA, Eduardo Romero de. Oficinas e depósitos ferroviários: identificação e análise de algumas companhias férreas paulistas (1867-1930). Pós. Revista do Programa de Pós-Graduação em Arquitetura e Urbanismo da FAUUSP, 26(48), e145345. <https://doi.org/10.11606/issn.2317-2762.posfau.2019.145345>.

SILVA, Tainá Maria. Oficinas ferroviárias em São Paulo: um estudo sobre a formação espacial da oficina da Companhia Paulista em Jundiaí (1892-1896). 2019. 168 f. Dissertação (Mestrado em Arquitetura e Urbanismo). Faculdade de Artes, Arquitetura e Comunicação, Universidade Estadual Paulista "Júlio de Mesquita Filho", Bauru, 2019. Disponível em: <http://hdl. handle.net/11449/190802>

SOUZA, Eliara Beck. AMORA, Ana Maria Gadelha Albano. O asylo da mendicidade e os planos urbanísticos do século XIX no Rio de Janeiro. URBANA, V.6, nº 8, jun.2014. Dossiê: Cidade e Habitação na América Latina - CIEC/UNICAMP.

WINPENNY, Thomas R. Without fitting, filing, or chipping: na illustrated history of the Phoenix 
Bridge Company. Easton Pennsylvania: Canal History and Technology Press, 1996.

\section{Anexo - Tabela de Pontos da CPEF - 1870 a 1910}

\begin{tabular}{|c|c|c|c|c|c|c|c|}
\hline $\begin{array}{l}\text { Ponto } \\
\text { kilométrico }\end{array}$ & Ramal & $\begin{array}{l}\text { Rio ou } \\
\text { Córrego }\end{array}$ & $\begin{array}{l}\text { Cidade/ } \\
\text { Distrito }\end{array}$ & $\begin{array}{c}\text { Ano de } \\
\text { construção }\end{array}$ & Extensão & $\begin{array}{c}\text { Material e sistema } \\
\text { construtivo }\end{array}$ & Profissionais \\
\hline- & - & Jundiaí & Jundiaí & 1870 & $11 \mathrm{~m}$ & $\begin{array}{l}\text { Material metálico; } \\
\text { alvenaria com cal } \\
\text { de Sorocaba }\end{array}$ & $\begin{array}{l}\text { Construtores: Angelo Thomaz } \\
\text { do Amaral, Heitor Rademaker } \\
\text { Grünewald e João Pereira } \\
\text { Darrigue Faro }\end{array}$ \\
\hline- & - & Guapeva & Jundiaí & 1870 & $6,4 \mathrm{~m}$ & Material metálico & $\begin{array}{l}\text { Construtores: Angelo Thomaz } \\
\text { do Amaral, Heitor Rademaker } \\
\text { Grünewald e João Pereira } \\
\text { Darrigue Faro }\end{array}$ \\
\hline- & - & Jundiaí-mirim & - & 1870 & $6,4 \mathrm{~m}$ & Material metálico & $\begin{array}{l}\text { Construtores: Angelo Thomaz } \\
\text { do Amaral, Heitor Rademaker } \\
\text { Grünewald e João Pereira } \\
\text { Darrigue Faro }\end{array}$ \\
\hline- & - & Pinheiros & Torrinha* & 1870 & $6,4 \mathrm{~m}$ & Material metálico & - \\
\hline- & - & - & $\begin{array}{l}\text { Dois } \\
\text { Córregos }\end{array}$ & 1870 & $5,5 \mathrm{~m}$ & Material metálico & - \\
\hline- & - & Capivary & Jundiaí & 1870 & - & - & $\begin{array}{l}\text { Construtores: Angelo Thomaz } \\
\text { do Amaral, Heitor Rademaker } \\
\text { Grünewald e João Pereira } \\
\text { Darrigue Faro }\end{array}$ \\
\hline 90 & $\begin{array}{l}\text { Jundiaí - } \\
\text { Cordeiro }\end{array}$ & Piracicaba & - & 1874 & $45 m$ & - & $\begin{array}{l}\text { Projeto: Andrew Handyside } \\
\& \text { Co }\end{array}$ \\
\hline- & - & $\begin{array}{l}\text { Ribeirão das } \\
\text { Araras }\end{array}$ & - & 1876 & - & - & - \\
\hline- & - & - & - & 1876 & - & Chapa de ferro & $\begin{array}{l}\text { Pessoal das oficinas de } \\
\text { Campinas }\end{array}$ \\
\hline- & - & - & - & 1876 & - & Chapa de ferro & $\begin{array}{l}\text { Pessoal das oficinas de } \\
\text { Campinas }\end{array}$ \\
\hline- & - & - & - & 1876 & - & Chapa de ferro & $\begin{array}{l}\text { Pessoal das oficinas de } \\
\text { Campinas }\end{array}$ \\
\hline- & - & Santa Rosa & $\begin{array}{l}\text { Mogi } \\
\text { Guaçu ou } \\
\text { Descalvado } \\
\text { ou Porto } \\
\text { Ferreira. }\end{array}$ & $1880 *$ & - & $\begin{array}{l}\text { Viga em chapa de } \\
\text { ferro }\end{array}$ & $\begin{array}{l}\text { Empreiteiros: Antonio Teixeira } \\
\text { da Silva e Angelo Fenili* }\end{array}$ \\
\hline
\end{tabular}




\begin{tabular}{|c|c|c|c|c|c|c|c|}
\hline- & $\begin{array}{c}\text { Pirassununga } \\
\text { - Porto } \\
\text { Ferreira }\end{array}$ & Mogi Guaçu & $\begin{array}{l}\text { Porto } \\
\text { Ferreira }\end{array}$ & 1880 & $97 \mathrm{~m}$ & $\begin{array}{l}\text { Madeira com } \\
\text { peças metálicas } \\
\text { fundidas e } \\
\text { moldadas nas } \\
\text { oficinas da } \\
\text { Companhia; } \\
\text { possui lanços } \\
\text { de vigamento } \\
\text { assentado } \\
\text { sobre pegões } \\
\text { de madeira. } \\
\text { Os pegões de } \\
\text { dentro do rio } \\
\text { são assentados } \\
\text { sobre rocha e } \\
\text { os das margens } \\
\text { sobre soleiras de } \\
\text { madeira }\end{array}$ & $\begin{array}{l}\text { Construtor: José Rodrigues } \\
\text { Ramos } \\
\text { Aterro preparado por João Val } \\
\text { Montini } \\
\text { Engenheiro autor do projeto: } \\
\text { Francisco Lobo Leite Pereira* }\end{array}$ \\
\hline $\begin{array}{l}\text { Ponto } \\
\text { kilométrico }\end{array}$ & Ramal & $\begin{array}{l}\text { Rio ou } \\
\text { Córrego }\end{array}$ & $\begin{array}{l}\text { Cidade/ } \\
\text { Distrito }\end{array}$ & $\begin{array}{c}\text { Ano de } \\
\text { construção }\end{array}$ & Extensão & $\begin{array}{c}\text { Material e sistema } \\
\text { construtivo }\end{array}$ & Profissionais \\
\hline 8 & Sta. Veridiana & Mogi Guaçu & $\begin{array}{c}\text { Cachoeira de } \\
\text { Emas }\end{array}$ & 1881 & - & - & Francisco Antonio Candido \\
\hline- & - & $\begin{array}{l}\text { Ribeirão } \\
\text { Bonito }\end{array}$ & Descalvado & 1881 & $11,8 \mathrm{~m}$ & $\begin{array}{l}\text { Material } \\
\text { encomendado } \\
\text { da Europa. } \\
\text { Vigas metálicas } \\
\text { produzidas } \\
\text { nas oficinas da } \\
\text { Companhia }\end{array}$ & - \\
\hline- & - & Tatu & - & 1883 & $10 \mathrm{~m}$ & $\begin{array}{l}\text { Madeira, } \\
\text { posteriormente } \\
\text { substituída por } \\
\text { ferro }\end{array}$ & - \\
\hline- & - & Tatu & - & 1883 & $10 \mathrm{~m}$ & $\begin{array}{l}\text { Madeira, } \\
\text { posteriormente } \\
\text { substituída por } \\
\text { ferro }\end{array}$ & - \\
\hline- & - & - & $\begin{array}{l}\text { Porto } \\
\text { Ferreira }\end{array}$ & 1884 & $8 m$ & - & - \\
\hline 105 & - & - & - & 1885 & - & - & - \\
\hline 99 & - & - & - & 1885 & - & $\begin{array}{l}\text { Madeira, } \\
\text { substituída } \\
\text { posteriormente } \\
\text { por ferro }\end{array}$ & - \\
\hline- & - & Corumbataí & - & $1888^{*}$ & - & $\begin{array}{l}\text { Madeira e ferro. } \\
\text { Alvenaria de } \\
\text { pedra }\end{array}$ & $\begin{array}{l}\text { Construída pela Companhia } \\
\text { Rio Claro }\end{array}$ \\
\hline- & - & Jacaré-pepira & - & $1888^{*}$ & - & $\begin{array}{l}\text { Madeira*. } \\
\text { Alvenaria de } \\
\text { pedra }\end{array}$ & $\begin{array}{l}\text { Construída pela Companhia } \\
\text { Rio Claro }\end{array}$ \\
\hline 97 & - & - & $\begin{array}{l}\text { Região } \\
\text { de Tatu e } \\
\text { Limeira* }\end{array}$ & $1888^{*}$ & - & $\begin{array}{l}\text { Madeira, } \\
\text { substituída } \\
\text { posteriormente } \\
\text { por ferro }\end{array}$ & - \\
\hline 95 & - & - & - & $1888^{*}$ & - & $\begin{array}{l}\text { Madeira, } \\
\text { substituída } \\
\text { posteriormente } \\
\text { por ferro }\end{array}$ & - \\
\hline
\end{tabular}




\begin{tabular}{|c|c|c|c|c|c|c|c|}
\hline $8 *$ & Sta. Veridiana & Mogi Guaçu & $\begin{array}{l}\text { Cachoeira de } \\
\text { Emas* }\end{array}$ & 1889 & $118 m$ & $\begin{array}{l}\text { Viga metálica } \\
\text { (encomendada). } \\
\text { Alvenaria de } \\
\text { pedra sobre rocha }\end{array}$ & $\begin{array}{l}\text { Projeto: Gabriel Ozorio de } \\
\text { Almeida } \\
\text { Empreiteiros: Aurelio Villa } \\
\text { Nova \& Comp } \\
\text { Pintor: Francisco Emílio }\end{array}$ \\
\hline 60 & - & $\begin{array}{c}\text { Ribeirão da } \\
\text { Onça }\end{array}$ & - & $1892 *$ & - & Madeira & - \\
\hline 21 & - & - & - & $1893 *$ & $20,7 m$ & - & - \\
\hline 112 & Jaú & Jacaré & Itirapina* & $1893^{*}$ & $13,7 \mathrm{~m}$ & - & Hyland Huggins* \\
\hline- & - & $\begin{array}{l}\text { Monte } \\
\text { Alegre }\end{array}$ & $\begin{array}{l}\text { Região de } \\
\text { Ribeirão } \\
\text { Preto* }\end{array}$ & $1893^{*}$ & $12 \mathrm{~m}$ & Ferro & - \\
\hline- & - & Bonfim & $\begin{array}{l}\text { Região de } \\
\text { Cravinhos* }\end{array}$ & $1893^{*}$ & $12 m$ & Ferro & - \\
\hline $\begin{array}{c}\text { Ponto } \\
\text { kilométrico }\end{array}$ & Ramal & $\begin{array}{l}\text { Rio ou } \\
\text { Córrego }\end{array}$ & $\begin{array}{l}\text { Cidade/ } \\
\text { Distrito }\end{array}$ & $\begin{array}{c}\text { Ano de } \\
\text { construção }\end{array}$ & Extensão & $\begin{array}{c}\text { Material e sistema } \\
\text { construtivo }\end{array}$ & Profissionais \\
\hline- & - & Rico & - & $1893^{*}$ & $12 \mathrm{~m}$ & Ferro & - \\
\hline- & - & Atibaia & Campinas & 1900 & $46 m$ & Ferro & - \\
\hline- & - & Trindade & $\begin{array}{l}\text { Região de } \\
\text { Jau* }^{*}\end{array}$ & $1902 *$ & $10 \mathrm{~m}$ & - & - \\
\hline $149 *$ & - & Jaú & Jaú & $1902 *$ & $20 m$ & - & - \\
\hline- & - & - & Pouso Alegre & $1902 *$ & $15 \mathrm{~m}$ & - & - \\
\hline- & - & Mogi Guaçu & Mogi Guaçu & 1902 & $101 \mathrm{~m}$ & Aço doce & $\begin{array}{l}\text { Superestrutura: The Phoenix } \\
\text { Bridge Co } \\
\text { Execução: Eng. Flavio de } \\
\text { Mendonça Uchôa }\end{array}$ \\
\hline- & - & Tietê & Pederneiras & 1903 & $385 m$ & & $\begin{array}{l}\text { Projeto: Ayrosa Galvão } \\
\text { Empreiteiro: Sebastião Oliveira } \\
\text { Damas } \\
\text { Montagem da estrutura } \\
\text { metálica: pessoal da } \\
\text { Companhia } \\
\text { Supervisão: Balbino Peçanha } \\
\text { Pintura: Joaquim Dutra } \\
\text { Engenheiro Residente: Roberto } \\
\text { Marinho de Azevedo }\end{array}$ \\
\hline 178 & - & Roque* & - & $1905^{*}$ & - & - & - \\
\hline- & - & Jundiaí-mirim & - & 1907 & - & $\begin{array}{l}\text { Madeira e trilhos } \\
\text { usados }\end{array}$ & - \\
\hline- & - & $\begin{array}{c}\text { Barra Seca } \\
\text { e Areia } \\
\text { Branca* }\end{array}$ & Bauru* & $1910 *$ & $20 m$ & - & - \\
\hline
\end{tabular}

\section{Legenda:}

* Dado impreciso ou carente de confirmação.

-- Não identificado nos relatórios 